\title{
Equine arteritis virus cytopathic effect: caspase- dependent cell death as the major consequence observed
}

\begin{abstract}
Equine arteritis virus infection in horse populations could be confirmed by the OIE recommended Virus Neutralization (VN) test and by the gold standard Virus Isolation (VI). These two techniques involve the observation of the cytopathic effect (CPE) of EAV. The characteristic CPE in EAV infections is the cellular lysis. The presence/ absence of this CPE in cells in the VI/VN respectively, indicate the positivity of each test.

CPE refers to morphological and molecular changes that where evidence in infect cells after viral infections. Most viral infections eventually result in the death of the host cell by different cellular mechanisms. The causes of death include cell lysis by alterations to the cell's surface membrane and by various modes of programmed cell death such as necrosis, apoptosis, autophagy and others. EAV CPE is always refers as cellular lysis but the mechanism involve in this lytical effect has never specifically determined. So, our objective is to extend the concept of the cytopathic effect of EAV infections. To study the effect of different cell death mechanism in EAV CPE we used different inhibitors. Consequently, we concluded that the most important mechanism of cell death in EAV infections is caspase-dependent cell death.
\end{abstract}

Keywords: equine arteritis virus, cytopathic effect, caspase-dependent cell death
Volume 2 Issue 4 - 2018

\author{
Abeyá MM,' Metz GE,' Franco Cruz R, ${ }^{2}$ \\ Correas I, ${ }^{2}$ Osorio FA, ${ }^{2}$ Echeverría MG' \\ 'Virology, Faculty of Veterinary Sciences, National University of \\ La Plata, Argentina \\ ${ }^{2} S$ chool of Veterinary Medicine and Biomedical Sciences, \\ University of Nebraska-Lincoln, USA
}

\begin{abstract}
Correspondence: German Ernesto Metz,Virology, Faculty of Veterinary Sciences, National University of La Plata, La Plata, Argentina; Members of CONICET (CCT-La Plata), Argentina, Tel +54 (022I) 4824956, Email germanmetz@conicet.gov.ar
\end{abstract}

Received: June 08, 2018 | Published: July 05, 2018
Abbreviations: VN, virus neutralization; VI, virus isolation; $\mathrm{EAV}$, equine arteritis virus; CPE, cytopathic effect; $\mathrm{MOI}$, multiplicity of infection; FBS, fetal bovine serum; MEM, minimal essential medium; PI, postinfection

\section{Short Communication}

The order Nidovirales comprises the families Arteriviridae, Coronaviridae, Mesoniviridae, and Roniviridae. ${ }^{1}$ Equine arteritis virus (EAV) is the prototype member of the family Arteriviridae and it has been grouped solely in the new genus Equarterivirus. ${ }^{2} \mathrm{EAV}$ is a small enveloped virus with a $12.7-\mathrm{kb}$ positive-sense single-stranded RNA genome which includes ten functional open reading frames. ${ }^{3} \mathrm{EAV}$ is an important equine respiratory virus causing equine viral arteritis (EVA). The majority of naturally acquired infections due to EAV are subclinical but if clinical signs are present they can vary in range and severity. ${ }^{4}$ Sporadic occurrence of clinical disease are characterized principally by fever, edema, anorexia, urticarial-type skin reaction, conjunctivitis, abortion and rarely, a fulminating pneumonia, enteritis or pneumoenteritis in young foals. A carrier state can occur in a variable percentage of infected stallions, but not in mares, geldings or sexually immature colts. The carrier state in infected stallion occurs for a variable period of time and there is no evidence of intermittence in virus shedding.

Viral infection in horse populations could be confirmed by the OIE recommended Virus Neutralization (VN) test and by the gold standard Virus Isolation (VI). These two techniques involve the observation of the cytopathic effect (CPE) of EAV. The characteristic CPE in EAV infections is the cellular lysis. The presence/absence of this CPE in cells in the VI/VN respectively, indicate the positivity of each test.
CPE refers to morphological and molecular changes that where evidence in infect cells after viral infections. Most viral infections eventually result in the death of the host cell by different cellular mechanisms. ${ }^{5}$ The causes of death include cell lysis by alterations to the cell's surface membrane and by various modes of programmed cell death such as necrosis, apoptosis, autophagy and others. EAV CPE is always refers as cellular lysis but the mechanism involve in this lytical effect has never specifically determined. So, our objective is to extend the concept of the cytopathic effect of EAV infections.

To study the effect of different cell death mechanism in EAV CPE we used different inhibitors. Each inhibitor was pre-incubated in cell monolayer for one hour prior viral infections in order to block a specific cell death pathway. After viral infection the inhibitors were reseeded and maintained until cell harvest. The investigation was done using Vero E6 cell line as a sensitive cell culture for EAV. ${ }^{6,7}$ Monolayers with $80 \%$ confluency arranged in 12-well plates were used and infected with the reference EAV strain, Bucyrus (Pubmed Reference: DQ846750) at a multiplicity of infection (MOI) of 1 . The monolayers were incubated for one hour at $37^{\circ} \mathrm{C}$ in an atmosphere with $5 \% \mathrm{CO}_{2}$. Then, the inoculum was removed and maintained in Minimal Essential Medium (MEM) with 2\% fetal bovine serum (FBS) and with each inhibitor at same concentration. All samples analyzed in this experiment were harvested at $72 \mathrm{~h}$ postinfection (pi), which is the standardized time at the maximal CPE evidenced in EAV-infected cells. ${ }^{8}$ Uninfected cultures were used as negative controls. Each of the experiment described was done by triplicate.

The samples were processed for cytometry following the commercial protocol (Thermo Fisher Scientific). After resuspending the cells, they were labeled with $5 \mu$ l Annexin V-FICT $(100 \mu \mathrm{g} /$ 
$\mathrm{ml}$, BioLegand) / $1 \mu \mathrm{l}$ Propidium Iodide $(50 \mu \mathrm{g} / \mathrm{ml}$, Thermo Fisher Scientific) and subjected to cytometry. After analyzing 10,000 events, the results were plotted using the Flow Jo program. The figures were displayed in different quadrants as follow: the lower left quadrants (Q4) refer to intact cells (Annexin $\mathrm{V}-$, PI-); the lower right quadrants (Q3) represent early apoptotic cells (Annexin V+, PI-) and the upper right quadrants (Q2) refer to late apoptotic and/or necrotic cells (Annexin $\mathrm{V}+, \mathrm{PI}+$ ). The control monolayers of uninfected Vero E6 cells showed a percentage of $81.9 \%$ live cells (Figure 1A, Q4 quadrant), that was reduced dramatically to $37.5 \%$ in EAV-infected Vero E6 cells (Figure 1B, Q4 quadrant).

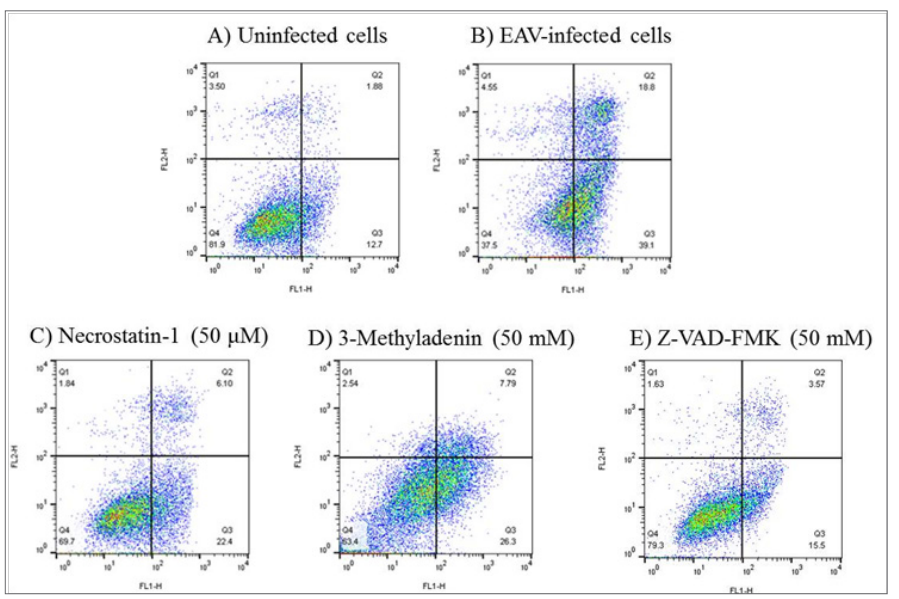

Figure I Flow cytometry of control and treated cell monolayers with each inhibitor. Q4 quadrant showed the percentage of cell survival in each experiment.

A) uninfected cells:81.9\%;

B) EAV-infected cells:37.5\%;

C) Necrostatin-I $(50 \mu \mathrm{M}): 69.7 \%$;

D) 3-Methyladenin $(50 \mathrm{mM}): 63.4 \%$.

E) ZVA-D-FMK $(50 \mathrm{mM}): 79.3 \%$.

To analyze the necrosis involve in the EAV CPE we used $1 \mu \mathrm{l}$ Necrostatin-1 $(50 \mu \mathrm{M}$, Abcam, Cambridge, MA), a recognized inhibitor of RIPK1 kinase in the necrosis process. ${ }^{9}$ The cytometry showed in this case a percentage of cell survival of $69.7 \%$ (Figure $1 \mathrm{C}, \mathrm{Q} 4$ quadrants). As it was not reached the percentage of $81.9 \%$ of cell survival as in the uninfected culture it was assumed that should exists other form of cell death in EAV-infected cells. To analyze the autophagy involve in the EAV CPE we used $1 \mu$ l of autophagy inhibitor 3-Methyladenin (50 mM, Sigma-Aldrich). 3-Methyladenin inhibits autophagy by blocking autophagosome formation via the inhibition of type III phosphatidylinositol 3-kinases (PI-3K). ${ }^{10}$ In this case, we obtained a percentage of $63.4 \%$ of survival cells (Figure 1D, Q4 quadrants) indicating that the autophagy mechanism was not the main mechanism in cell death in EAV infection.

Finally, we studied the importance of caspase-dependent cell death in the CPE of EAV-infected cells. For this purpose, we used as a pan-caspase inhibitor $1 \mu \mathrm{l}$ Z-VAD-FMK (50mM, Abcam, Cambridge, MA). This is a cell-permeant pan-caspase inhibitor that irreversibly binds to the catalytic site of caspases and can inhibit induction of all kinds of caspase-dependent cell death. ${ }^{11}$ When this cell death pathway was inhibited in infected cultures we observed the percentage of cell survival (79.3\%) (Figure 1E, Q4 quadrants) reached similar values as uninfected Vero E6 (81.9\%). Consequently, thus indicate the crucial importance of caspase-dependent cell death in the CPE of EAV infection. Several scientific papers reported the relations between EAV and cellular apoptosis., ${ }^{72-15}$ Nevertheless, this mechanism was never associated with the CPE of EAV infection in cell cultures. Consequently, in this easy set of experiments we concluded that the most important mechanism of cell death in EAV infections is caspasedependent cell death or saying in other words, EAV CPE is due to a caspase-dependent death.

\section{Conclusion}

We redefining equine arteritis virus cytopathic effect and point the caspase-dependent mechanism as the major consequence observed in cell cultures. The activity of individual and specific caspases must be analyzed to confirm the particular caspase/s that mediated the cell death mechanism particularly involved.

\section{Acknowledgments}

This work was supported by the BEC.ar program (Argentina) and by Proyecto de Incentivos Docentes (V221) de la Universidad Nacional de La Plata, Buenos Aires, Argentina. The authors declare that they have no conflict of interest.

\section{Conflict of interest}

The author declares no conflict of interest.

\section{References}

1. de Groot RJ, Cowley JA, Enjuanes L, et al. Order Nidovirales. Virus taxonomy. Ninth report of the international committee on taxonomy of viruses. Amsterdam: Elsevier Academic Press; 2012. p. 785-795.

2. Kuhn JH, Lauck M, Bailey AL, et al. Reorganization and expansion of the nidoviral family Arteriviridae. Arch Virol. 2016;161(3):755-768.

3. Snijder EJ, Meulenberg JJM. The molecular biology of arteriviruses. $J$ Gen Virol. 1988;79(pt 5):961-979.

4. Timoney PJ, McCollum WH. Equine viral arteritis. Vet Clin N Am Equine Pract. 1993;9(2):295-309.

5. Kroemer G, Galluzzi L, Vandenabeele P, et al. Classification of cell death: recommendations of the Nomenclature Committee on Cell Death. Cell Death Differ. 2009;16(1):3-11.

6. Timoney PJ, Bruser CA, McCollum WH, et al. Comparative sensitivity of LLCMK2, RK-13, Vero and equine dermis cell lines for primary isolation and propagation of equine arteritis virus. Proceedings of the International Workshop on the Diagnosis of Equine Arteritis Virus Infection; 2004 Oct 20-21; USA. Kentucky: Cluck Equine Research Center; 2004. p. 26-27.

7. Archambault D, St-Laurent G. Induction of apoptosis by equine arteritis virus infection. Virus Genes. 2000;20(2):143-147.

8. http://www.oie.int/fileadmin/Home/eng/Health_standards/tahm/2.05.10_ EVA.pdf

9. Degterev A, Hitomi J, Germscheid M, et al. Identification of RIP1 kinase as a specific cellular target of necrostatins. Nat Chem Biol. 2008;4(5):313321.

10. Wu JJ, Quijano C, Wang J, et al. Metabolism meets autophagy. Cell Cycle. 2010;9(24):4780-4781. 
11. Van Noorden CJ. The history of Z-VAD-FMK, a tool for understanding the significance of caspase inhibition. Acta Histochem. 2001;103(3):241251.

12. St-Louis MC, Archambault D. The equine arteritis virus induces apoptosis via caspase-8 and mitochondria-dependent caspase-9 activation. Virology. 2010;367(1):147-155.

13. Cholleti H, Paidikondala M, Munir M, et al. Equine arteritis virus induced cell death is associated with activation of the intrinsic apoptotic signalling pathway. Virus Res. 2013;171(1):222-226.
14. Metz GE, Serena MS, Abeyá MM, et al. Equine arteritis virus gP5 protein induces apoptosis in cultured insect cells. Virus Res. 2014;183:81-84.

15. Metz GE, Galindo I, Abeyá MM, et al. Intrinsic, extrinsic and endoplasmic reticulum stress-induced apoptosis in RK13 cells infected with equine arteritis virus. Virus Res. 2016;213:219-223. 